\title{
TREATMENT COMPLIANCE OF PEDIATRIC LATENT TUBERCULOSIS INFECTION: AN EXPERIENCE OF A TERTIARY HOSPITAL IN JEONBUK PROVINCE, KOREA, 2014-2017
}

Jin Woong Doo', Nu Ri Hwang', Min Jeong Han', Sun Jin Lee', Ki Hwan Kim², Jae Kyun Hur², Dae Sun Jo'

1 Department of Pediatrics, Chonbuk National University Children's Hospital, Jeonju, Republic of Korea

2 Department of Pediatrics, College of Medicine, Catholic University of Korea, Seoul, Republic of Korea

\section{$\odot$ Background}

According to the Korean Guidelines for Tuberculosis, a 9 month course of isoniazid $(9 H)$ or a 3 month course of isoniazid plus rifampin (3HR) is recommended for the patients of latent tuberculosis infection (LTBI). However, for childhood patients, it is hard to maintain medication for those period. We aimed this study to find what are the obstacles to good treatment compliance.

\section{Methods}

We reviewed the medical records of all

confirmed pediatric latent tuberculosis cases in Chonbuk National University Children's Hospital, from January 2014 through December 2017. Visit dates, symptoms and signs

possibly related to medication, and

prescription details were mainly investigated.

\section{- Keywords}

atent tuberculosis,

Child,

Treatment compliance

\section{$\odot$ Results}

A total of 232 medical records of childhood LTB cases were reviewed. Most children $(\mathrm{N}=225)$ were on $9 \mathrm{H}$. Seven adolescents completed $3 \mathrm{HR}$ and 3 of them mentioned orange colored urine. Sixteen children (6.9\%), mostly infants and on $9 \mathrm{H}$ showed refusal of medication in the early period of treatment but completed the course. Two infants had a few days of diarrhea but they could continue the medication. No cases in this study showed skin rash related to the medication. Twelve (5.2\%) cases completed the medication behind the schedule due to delaved clinic visits. All pediatric LTBI cases in this study completed a course of either $9 \mathrm{H}$ or $3 \mathrm{HR}$.

\section{Conclusions}

Adverse effects of childhood LTBI treatment were rare and tolerable. To complete the LTBI treatment course properly in children, reminding the visit schedules to caregivers are important. Providino reassurance to caregivers and easily administrable drug formula could improve the compliance for the LTBI treatment in children.

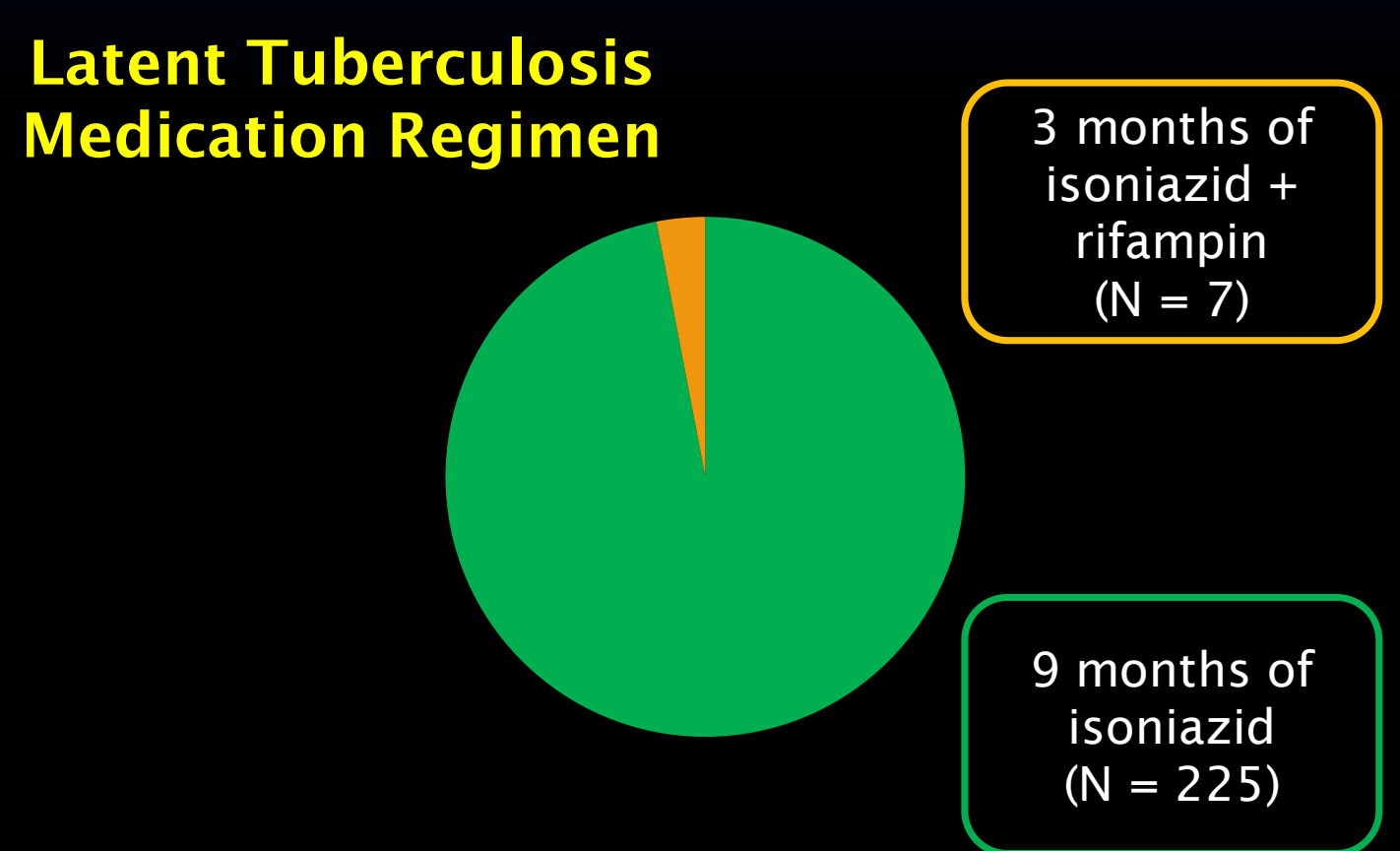

Adverse Effect Incidence in Pediatric Latent Tuberculosis Treatment

\begin{tabular}{l|c|c}
\hline $\begin{array}{l}\text { Adverse effects / } \\
\text { problem }\end{array}$ & $\begin{array}{c}\text { 9H group } \\
(\mathbf{N}=\mathbf{2 2 5})\end{array}$ & $\begin{array}{c}\text { 3HR group } \\
(\mathbf{N}=\mathbf{7})\end{array}$ \\
\hline Medication refusal & 16 & 0 \\
Diarrhea & 2 & 0 \\
$\begin{array}{l}\text { Orange colored urine } \\
\begin{array}{l}\text { Medication completion } \\
\text { behind the schedule }\end{array}\end{array}$ & 10 & 3 \\
$\begin{array}{l}\text { Incomplete course of } \\
\text { medication }\end{array}$ & 0 & 2 \\
\hline
\end{tabular}

$3 \mathrm{HR}, 3$ months of isoniazid plus rifampin; $9 \mathrm{H}, 9$ months of isoniazid 